\title{
Microstructure Evolution of W-Cu Alloy Wire after Hot-Swaging*
}

\author{
Fei Shao $^{1}$, Wenge Chen ${ }^{1}$, Hui Zhang ${ }^{1}$, Bingjun Ding ${ }^{2}$ \\ ${ }^{1}$ School of Materials Science and Engineering, Xi'an University of Technology, Xi'an, China; ${ }^{2}$ School of Science, Xi'an Jiaotong \\ University, Xi'an, China. \\ Email: shaofei0908@126.com
}

Received April 22 $2^{\text {nd }}, 2011$; revised December $8^{\text {th }}, 2011$; accepted January $19^{\text {th }}, 2012$

\begin{abstract}
Microstructure of $\mathrm{W}-\mathrm{Cu}$ alloy wire before and after hot-swaging was studied in this paper. Results show that a homogeneous microstructure of the $\mathrm{W}-\mathrm{Cu}$ alloy wire was formed after hot-swaging treatment, and the tungsten particles were embedded in copper phases to form a networking structure; the $\mathrm{W}-\mathrm{Cu}$ alloy wire has a microstructure of body-centered-cubic tungsten particles and face-centered-cubic copper phase, and did not change after hot-swaging. The intermediate phases have not been found during the process, but the size of the tungsten particles in the copper matrix becomes smaller. After hot-swaging, the treated W-Cu alloy wire has a relative density of $105.1 \%$, and a conductivity of $47.2 \%$ IACS, the tensile and bending strength can be as large as 644 and $1600 \mathrm{MPa}$, respectively.
\end{abstract}

Keywords: Hot-Swaging; Microstructure; W-Cu Alloy; Wire

\section{Introduction}

W-Cu alloy, one of the commonly known as pseudo alloy, is a kind of composite material composed by body centered cubic tungsten particles embedded inside face centered cubic copper. The alloy was neither mutual solution nor forming intermetallics. The $\mathrm{W}-\mathrm{Cu}$ alloys are widely used in many fields due to their outstanding properties which include high temperature and welding resistance, high strength, hardness, density and low expansion coefficient. They also have properties, such as high plasticity, arc erosion resistance, good conductive and thermal conductivity [1-6]. At present the main applications are in the heavy-duty electrical contacts, vacuum switch, electro-thermal alloy, high density alloy, resistance welding electrodes, contact tips of arc-welding guns, electrosparking and plasma electrode materials and heat sinks in electronic packages etc. [7-18]. It is often used as the electrode wire, with typical diameter of not more than 4 $\mathrm{mm}$.

The conventional preparation method of the $\mathrm{W}-\mathrm{Cu}$ alloy wire is drawing and rolling. This is because for this type of low plastic non-ferrous metal, the powder metallurgy method will cause many defects such as crazes, fracture, air bubble and holes, etc. These defects are difficult to remove thus results in low density and poor conductivity of the material. The hot-swaging with a good

*Foundation item: the National Natural Science Foundation of China, NO. 50834003. adaptability is widely applied to the preparation of the metal matrix wire in which the particles is not easy to dissolve each other $[19,20]$. So far, there is little work done to use hot-swaging method for the $\mathrm{W}-\mathrm{Cu}$ pseudo alloy $[21,22]$. In this paper, the microstructure evolution of $\mathrm{W}-\mathrm{Cu}$ alloy wire before and after hot-swaging was studied.

\section{Experimental Procedures}

Average particle sizes of tungsten and copper powders are in the range of $5-7 \mu \mathrm{m}$ and $45 \mu \mathrm{m}$ respectively. The two powders were mechanically mixed in a high-strength container for 6 hours in an isopropanol solution. The formed mixed powder was pressed into pellets under a pressure of 6 to $8 \mathrm{t} / \mathrm{cm}^{2}$ followed by sintering at $1350^{\circ} \mathrm{C}$ in a sintering furnace with hydrogen atmosphere.

The hot-swaging process of the W70Cu30 alloy was conducted using a CF116-2/ZF rotary swaging machine at the temperature of $750^{\circ} \mathrm{C}$ with a frequency between 6800 and 12,000. (Frequency should be Hz!!) The difference in diameter for the successive swaging processes is 0.4 millimeter. In the hot-swaging process, forging hammer and forging die rotate with the spindle and under the action of centrifugal force and pressure of the spindle do reciprocating motion along radial direction in the high frequency. And under the influence of the Contact friction between forging hammer and roller column, the frame of the spindle also rotate with the spindle. The 
W70Cu30 wire not only move lengthily in axial direction but also rotate around the spindle in the effect of forging twisting couple. The final dimension of the $\mathrm{W}-\mathrm{Cu}$ alloy wire is $300 \mathrm{~mm}$ in length and 4 millimeters in diameter. Meanwhile, the contents of copper and tungsten are determined to be: $\mathrm{Cu}$ : titration (QB-H2-04.1-1999) 29.81\% and $70.19 \%$ respectively.

Microstructure of the W-Cu alloy wire before and after hot-swaging was observed using a Zeiss Axiovert 200 MAT metallographic microscope. Sodium hydroxide and potassium ferricyanide solutions were used as tungsten etchant. Ferric chloride hydrochloric acid corrosive $\left(\mathrm{FeCl}_{3}\right.$ : $30 \mathrm{~g}, \mathrm{HCl}: 15 \mathrm{ml}, \mathrm{H}_{2} \mathrm{O}: 100 \mathrm{ml}$ ) was used to etch the copper. JEM-3010 high-resolution transmission electron microscopy was adopted to identify the crystalline structures of the W-Cu alloy wire before and after hot-swaging. Tensile testing and bending test were conducted using an INSTRON 1195 tensile testing machine, according to GB/T228-2002 tensile testing standards.

\section{Results and Discussion}

\subsection{Microstructures Analysis of W70Cu30 Alloys That Uses Metallographic Microscopy}

The metallographic structure of the hot-swaged W70Cu30 alloy wire is shown in Figure 1. The white area and the grey areas seen in the picture are copper phase and tungsten phase, respectively. Before hot-swaging, it can been see in Figure 1(a), the W70Cu30 alloy grain structure is relatively large, and copper gathers together to form plates distributing inside the tungsten matrix. There are tiny black pores existed in the matrix, and the distribution of copper phases are not even. After hot-swaging, the microstructure is much finer, as seen in Figure 1(b). The distribution of the copper phases becomes much more uniform.

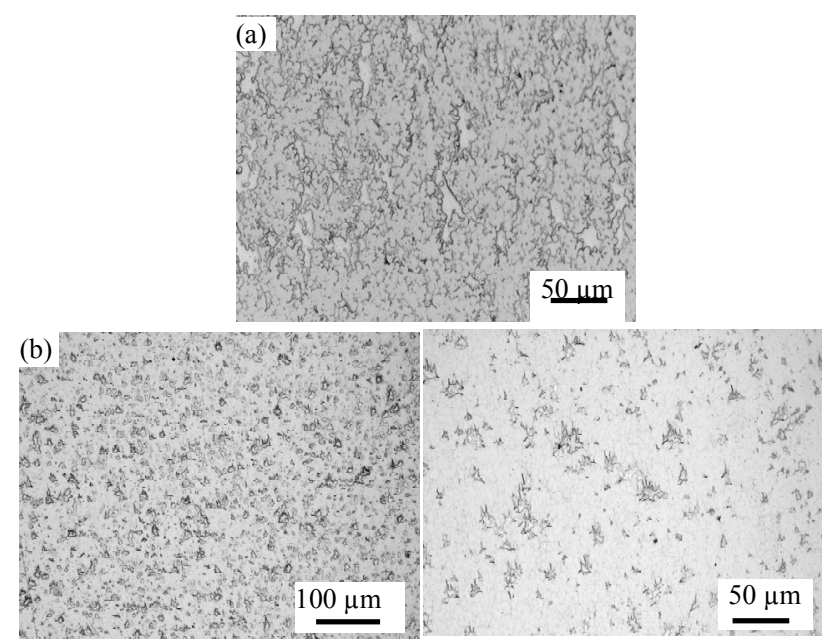

Figure 1. Microstructure of $\mathrm{W70Cu} 30$ wires before (a) and after (b) hot-swaging.
After hot-swaging, the corrosion micrographs of W70Cu30 alloy wire are shown in Figure 2. Obviously, the binding phase $\mathrm{Cu}$ presents is irregular shape but evenly distributes, as seen in Figure 2(a). The tungsten phase as skeleton has the morphology of strip-like shape, which is different from raw material powder in which the shape of tungsten particles is nearly spherical. Figure 2 (b) illustrates deformation has taken place between $\mathrm{W}$ particles by hot-swaging.

Comparing Figure 1(b) and Figure 2, it can be found that copper segregates together and the previous observed holes disappear. There is uniform distribution of copper phases and tungsten phases. Tungsten particles are embedded by copper phases to form a special kind of network microstructure. This is because during the swaging process, the wire was pressed in three directions, large compressive stress can make intragranular defects such as pores to disappear and reduce the many brittle phases. The $\mathrm{W}$ and $\mathrm{Cu}$ phases are welded together to from a homogeneous microstructure. The dimension change in each step of the swaging process is relatively small. The wire will bear circumferential compressive deformation distributed uniformly to eliminate the pores, holes and other defects in the materials and form finer grains after swaging. Therefore, the process makes the two phases mutually extruding, slipping, and making the structure compact and uniform.

Figure 3 presents vertical cross-section micrographs of the W70Cu30 alloy wire before and after hot-swaging. As seen in the picture, the black copper phase is gradually squeezed, the shape of which changes from blocks into strips, finally becomes much finer strips, and distributed uniformly inside the tungsten matrix.

Comparing Figure 1 and Figure 3, it can be found that the microstructures of the $\mathrm{W}-\mathrm{Cu}$ wires in vertical crosssection do not show many changes after the swaging process. The spherical tungsten particles are uniformly distributed in the copper phases. Before the swaging process, copper phases don't distribute evenly inside matrix but uniformity has been improved significantly after swaging. The Copper particles distributed uniformly along the vertical direction. While the Tungsten particles are squeezed more closely than before and start to extend
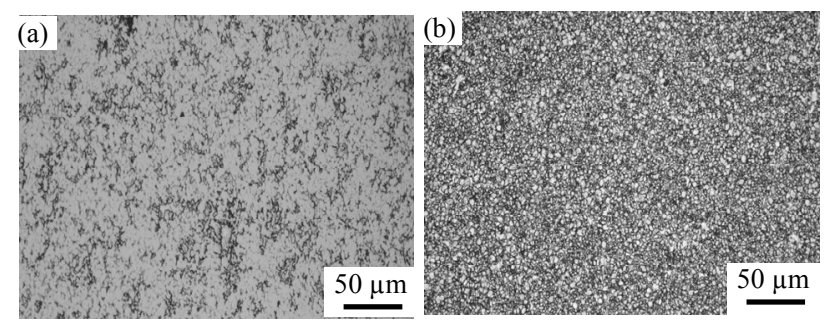

Figure 2. Microstructure of W70Cu30 wires after corrosion (a) tungsten (b) copper. 

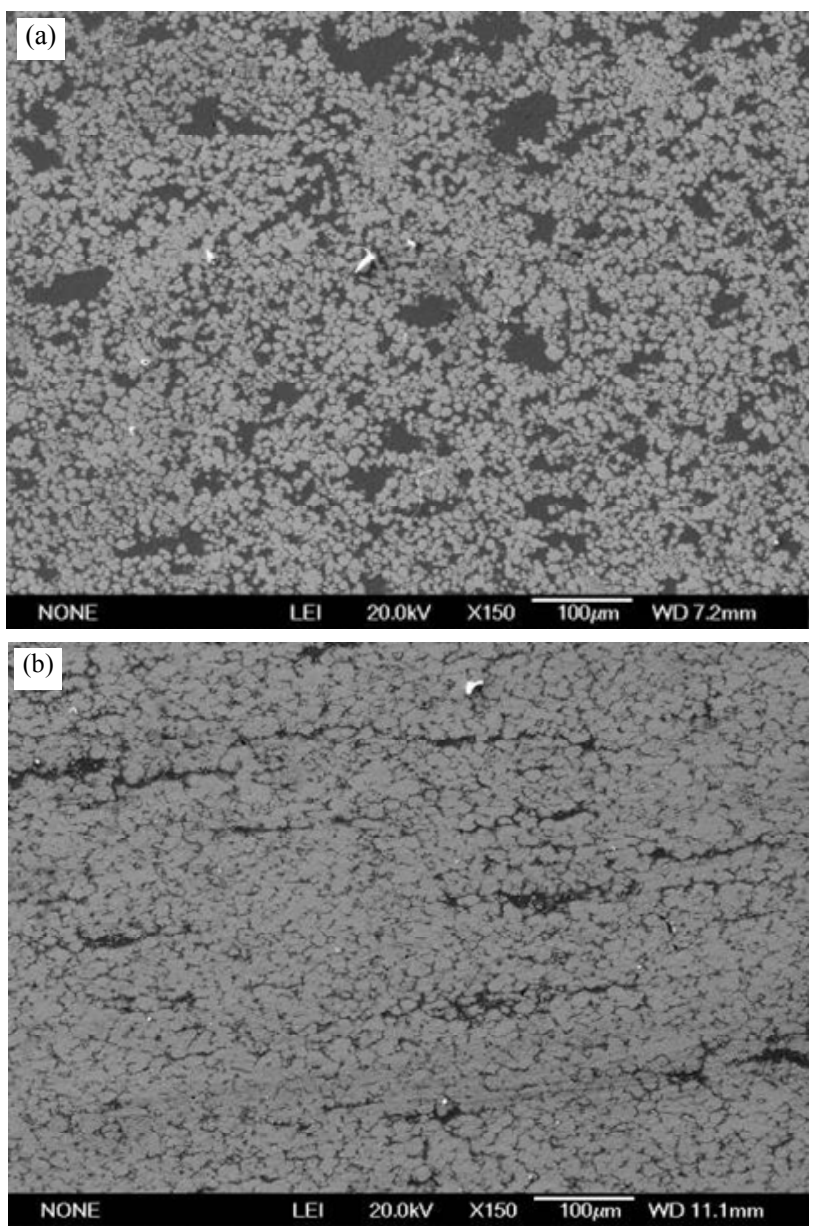

Figure 3. Microstructure of cross-section of W70Cu30 alloys before (a) and after (b) hot-swaging

in vertical section. The shape of most of tungsten particles is oval. There is the tendency that the strip-like copper phases appear, and the non-uniformly distribution of the Copper phases have been successfully improved. Therefore, owing to copper phases are squeezed, the fine and long strip-like copper phases emerge and distribute around the tungsten particles. Also the ratios of the length-diameter of the tungsten particles increase.

\subsection{Microstructures of W70Cu30 Alloys by Transmission Electron Microscope}

The micrographs of the W70Cu30 alloy wire from TEM analysis are shown in Figure 4. There are some black particles distributed inside the large grey area. Comparing Figure 3(a) with Figure 3(b), it can be seen that the size of black particles after hot-swaging is much smaller than that before hot-swaging.

The selected area diffraction was taken in the selected area of A and B shown in Figure 4, and the structure was identified as shown in Figure 5. It has been proved that the areas of $\mathrm{A}$ and $\mathrm{B}$ are tungsten and Copper phase,
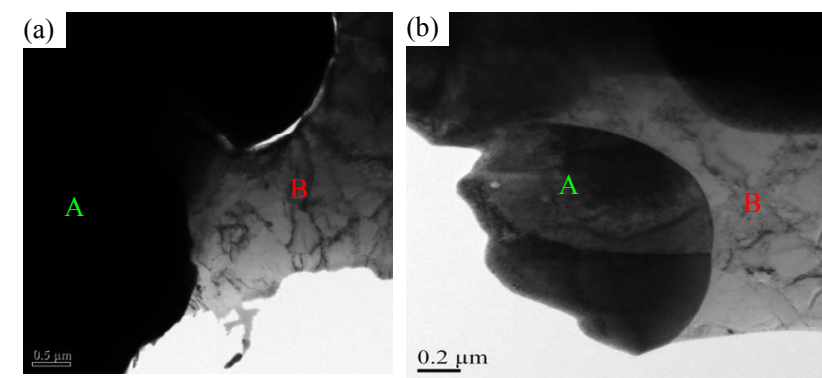

Figure 4. Microstructure of W70Cu30 alloy by transmission electron microscope before (a) and after (b) hot-swaging.
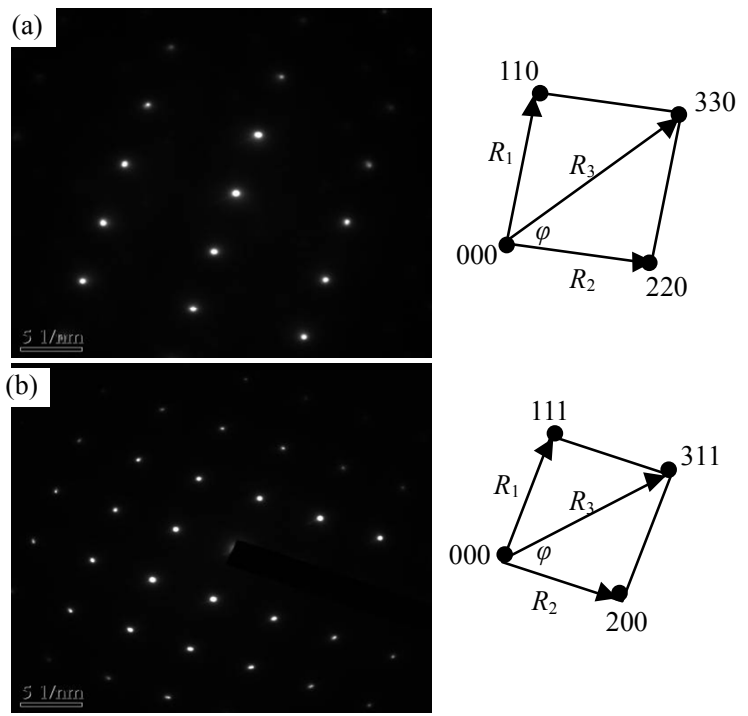

Figure 5. Diffraction pattern and calibrated graph of W70Cu30 wire before and after hot-swaging (a) A area; (b) B area.

respectively, and no intermediate phases formed. The structure of tungsten phase in A area is body centered cubic(BCC) and the structure of Copper phase in B area is face centered cubic(FCC).

In order to further define the composition of the W-Cu wire, energy dispersive X-ray analysis (EDX) was used in the areas of A and B. The results shown in Figure 6 proved that the composition of the $\mathrm{W}-\mathrm{Cu}$ wire in A area and in B area are tungsten phase and Copper phase only. The minor amount of $\mathrm{Cu}$ in Figure 5(a) might be from the sample stage of TEM which are made of copper.

It can be concluded that before or after hot-swaging, the structure in A area and B area are the body-centered cubic tungsten and face-centered cubic copper phases, respectively. The results have been shown by comparing Figure 4(a) with Figure 4(b) and that the tungsten particles are significantly finer and more uniformly dispersed in the copper matrix after swaging. After hotswaging, the pores, holes and other defects in the materials were eliminated, and $\mathrm{W}$ particles distribute more uniformly in the matrix. The big grains were changes into finer grains. Because the grain size gets smaller, it's 


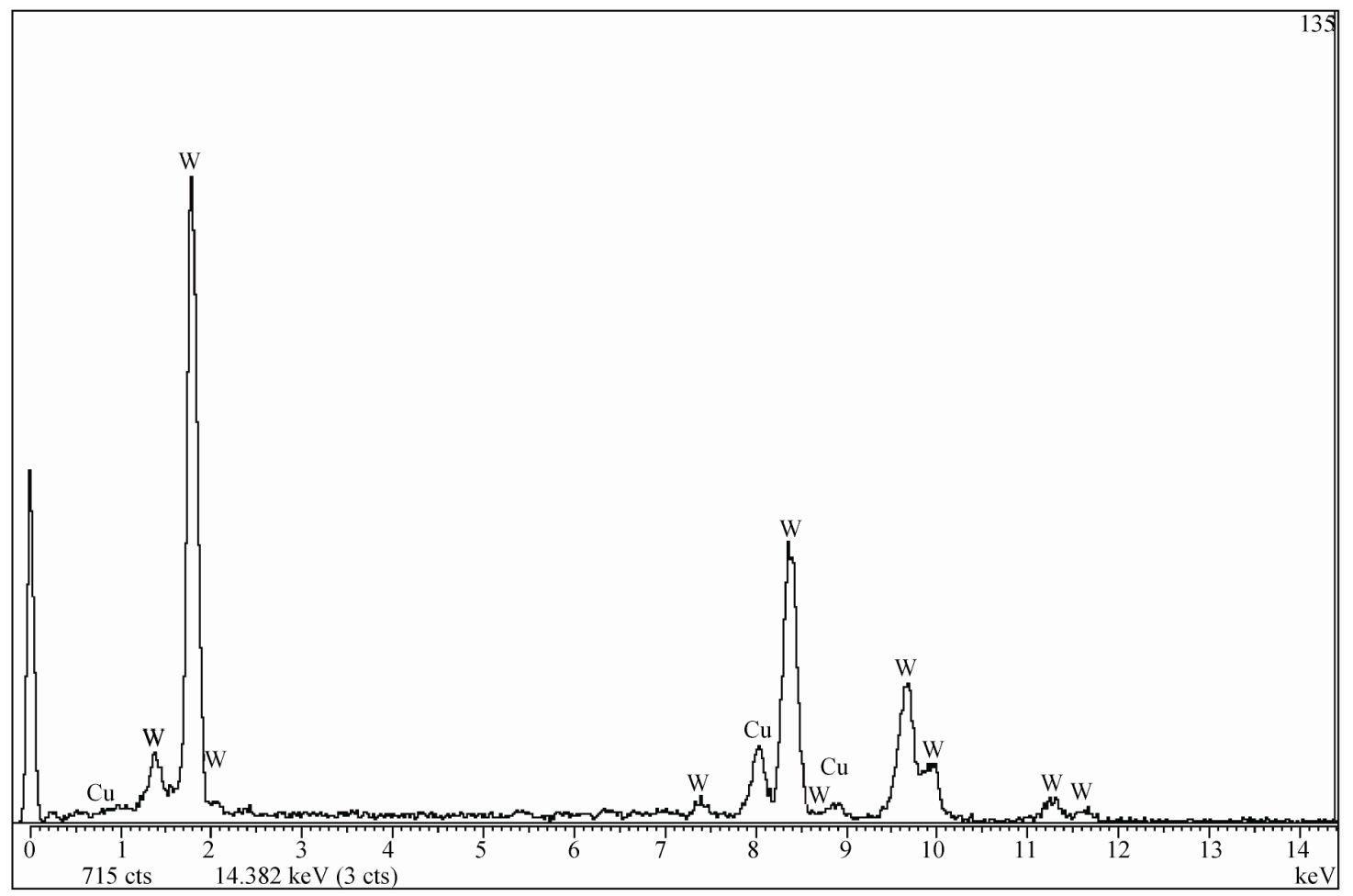

(a)

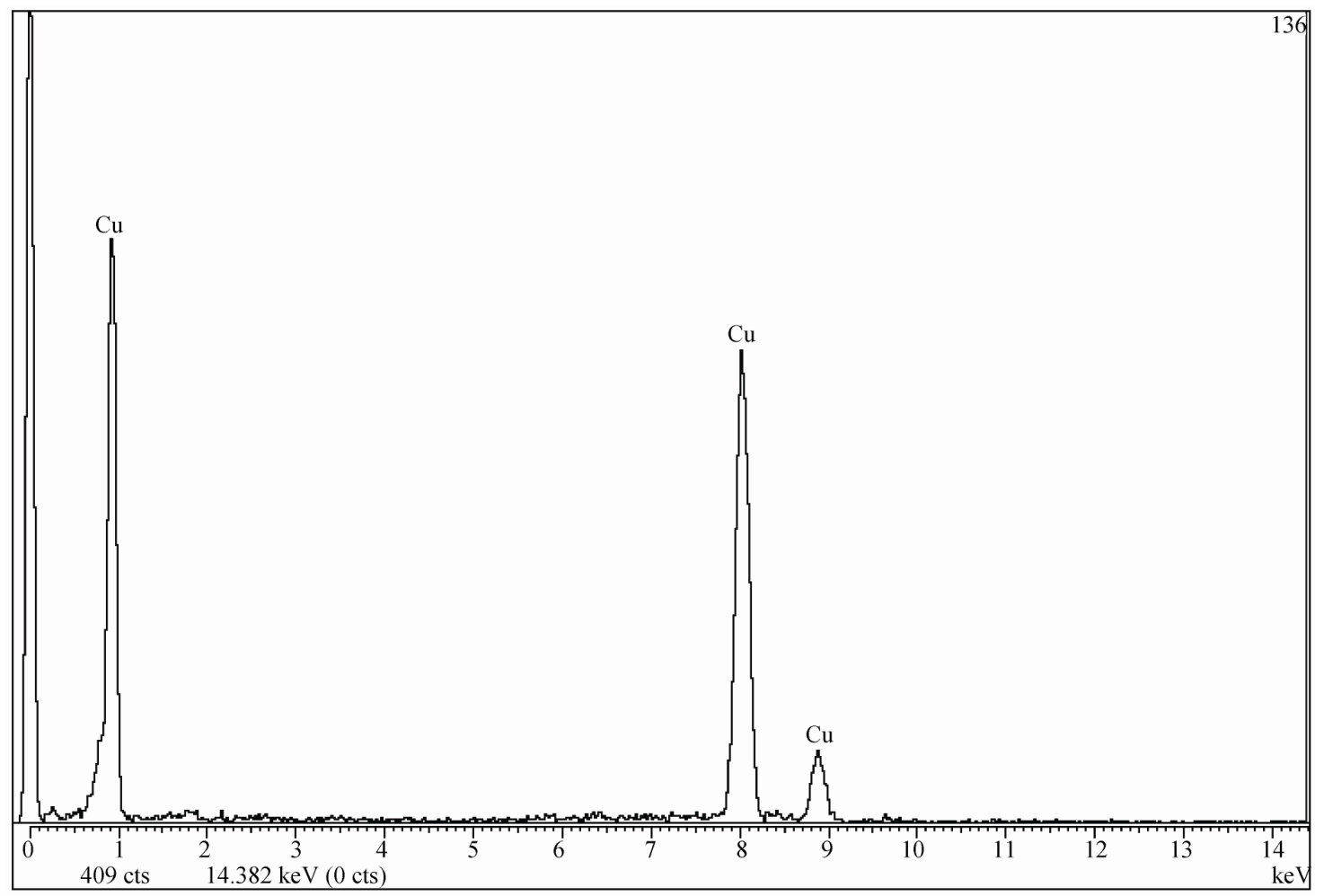

(b)

Figure 6. Spectrum diagrams of W70Cu30 wire before and after hot-swaging (a) A area; (b) B area.

the strength of the alloys also increases markedly. The properties of the $\mathrm{W} 70 \mathrm{Cu} 30$ alloy wire after swaging are listed in Table 1. Density, hardness and conductivity of the W70Cu30 alloy wires are much higher than those of 
Table 1. Mechanical property of W70Cu30 wires after hot-swaging.

\begin{tabular}{|c|c|c|c|c|}
\hline Properties & Density $/ \mathrm{g} / \mathrm{cm}^{3}$ & Relative density/\% & Hardness/HV & Conductivity/\%IACS \\
\hline Actual measurement data & 15.05 & 105.1 & 252 & 47.2 \\
\hline GB8320-2003 & 14.31 & 96.43 & 184 & 42.1 \\
\hline
\end{tabular}

the national standard (GB8320-2003). After swaging, the tensile strength and bending strength of W70Cu30 are $644 \mathrm{MPa}$ and $1600 \mathrm{MPa}$ respectively, relatively higher than those before swaging.

\section{Conclusions}

1) Uniformity of the microstructure of the W-Cu alloy wire was formed after hot-swaging treatment, and the tungsten particles were embedded in copper phases to form a networking structure; the $\mathrm{W}-\mathrm{Cu}$ alloy wire has a microstructure of body-centered-cubic tungsten particles and face-centered-cubic copper phase, and did not change after hot-swaging. The intermediate phases have not been found during the process, but the size of the tungsten particles in the copper matrix becomes smaller.

2) After hot-swaging, the treated W-Cu alloy wire has a relative density of $105.1 \%$, and a conductivity of $47.2 \%$ IACS. The tensile and bending strength can be as large as 644 and $1600 \mathrm{MPa}$, respectively.

\section{Acknowledgements}

This work was financially supported by the National Natural Science Foundation of China (No.50834003).

\section{REFERENCES}

[1] W. G. Chen, M. Z. Chen and L. Q. Qian, "Effect of Doping on Electrical Arc Characteristic of W-Cu Electrical Contact Materials," The Chinese Journal of Nonferrous Metals, Vol. 19, No. 11, 2009, pp. 2029-2036.

[2] M. Ardestani, H. Arabi, H. R. Rezaie and H. Razavizadeh, "Synthesis and Densification of $\mathrm{W}-30 \mathrm{wt} \% \mathrm{Cu}$ Composite Powders Using Ammonium Meta Tungstate and Copper nitrate as Precursors," International Journal of Refractory Metals and Hard Materials, Vol. 27, No. 4, 2009, pp. 796800. doi:10.1016/j.ijrmhm.2009.01.001

[3] S. S. Ryu, Y. D. Kim and I. H. Moon, "Dilatometric Analysis on the Sintering Behavior of Nanocrystalline W-Cu Prepared by Mechanical Alloying," Journal of Alloys and Compounds, Vol. 335, No. 1-2, 2002, pp. 233240. doi:10.1016/S0925-8388(01)01805-9

[4] L. Li, Y. S. Wong, J. Y. H. Fuh and L. Li, " Effect of TiC in Copper-Tungsten Electrodes on EDM Performance," Journal of Materials Processing Technology, Vol. 113, No. 1-3, 2001, pp. 563-567. doi:10.1016/S0924-0136(01)00622-7

[5] W. G. Chen, Z. Y. Kang, H. F. Shen and B. J. Ding, “Arc Erosion Behavior of a Nanocomposite W-Cu Electrical Contact Material," Rare Metals, Vol. 25, No. 1, 2006, pp.
37-42. doi:10.1016/S1001-0521(06)60011-9

[6] Z. L. Wang, X. J. Li, J. Q. Zhu, F. Mo, C. F. Zhao and L. $\mathrm{H}$. Wang, "Dynamic Consolidation of W-Cu Nanocomposites from W-CuO Powder Mixture," Materials Science and Engineering, Vol. 527, No. 21-22, 2010, pp. 60986101. doi:10.1016/j.msea.2010.05.077

[7] Y. J. Lee, B. H. Lee, G. S. Kim, D. G. Kim, D. S. Kim and Y. D. Kim, "Evaluation of Conductivity in W-Cu Composites through the Estimation of Topological Microstructures," Materials Letters, Vol. 60, No. 16, 2006, pp. 2000-2003. doi:10.1016/i.matlet.2005.12.113

[8] S. P. Wen, R. L. Zong, F. Zeng, Y. Gao and F. Pan, "Evaluating Modulus and Hardness Enhancement in Evaporated $\mathrm{Cu} / \mathrm{W}$ Multilayers," Acta Materialia, Vol. 55, No. 1, 2007, pp. 345-351. doi:10.1016/j.actamat.2006.07.043

[9] X. H. Yang, S. H. Liang, X. H. Wang, P. Xiao and Z. K. Fan, "Effect of $\mathrm{WC}$ and $\mathrm{CeO}_{2}$ on Microstructure and Properties of W-Cu Electrical Contact Material," International Journal of Refractory Metals and Hard Materials, Vol. 28, No. 2, 2010, pp. 305-311. doi:10.1016/j.ijrmhm.2009.11.009

[10] Z. F. Wang, Z. C. Liu and G. S. Jing, "Hermeticity of W-Cu Composites for Semiconductor Package," The Chinese Journal of Nonferrous Metals, Vol. 9, No. 2, 1999, pp. 323-326.

[11] D. M. Lu, "Tungsten Copper Materials Used in Vacuum Switches and Electronics," Powder Metallurgy Industry, Vol. 8, No. 6, 1998, pp. 32-35.

[12] W. P. Zhou, D. M. Lv, A. Q. Tang and X. Y. Ling, "Study of Manufacturing Process of WCu Electrode Materials for Electric Spark Machining," The Chinese Journal of Materials for Mechanical Engineering, Vol. 20, No. 2, 1996, pp. 30-32.

[13] R. G. Zhang, W. Lin, K. Lawrence and C. P. Wong, "Highly Reliable, Low Cost, Isotropic Ally Conductive Adhesives Filled with Ag-Coated Cu Flakes for Electronic Packaging Applications," International Journal of Adhesion and Adhesives, Vol. 30, No. 6, 2010, pp.403407. doi:10.1016/j.ijadhadh.2010.01.004

[14] Q. X. Zhang, Y. Gao, W. M. Jia and J. S. Chen, "Study of Mechanically Alloyed Cuw Shaped Charge Liner Materials," Ordnance Material Science and Engineering, Vol. 23, No. 3, 2000, pp. 44-50.

[15] D. G. Kim, S. T. Oh, H. Jeon, C. H. Lee and Y. D. Kim, "Hydrogen-Reduction Behavior and Micro Structural Characteristics of $\mathrm{WO}_{3}-\mathrm{CuO}$ Powder Mixtures with Various Milling Time," Journal of Alloys and Compounds, Vol. 354, No. 1-2, 2003, pp. 239-242. doi:10.1016/S0925-8388(03)00007-0

[16] Y. Hiraoka, H. Hanado and T. Inoue, "Deformation Behavior at Room Temperature of $\mathrm{W}-80$ vol $\% \mathrm{Cu}$ Composite," International Journal of Refractory Metals and Hard 
Materials, Vol. 22, No. 2-3, 2004, pp. 87-93. doi:10.1016/j.ijrmhm.2004.01.002

[17] Y. D. Kim, N. L. Oh, S. T. Oh, and I. H. Moon, "Thermal Conductivity of W-Cu Composites at Various Temperatures," Materials Letters, Vol. 51, No. 5, 2001, pp. 420424. doi:10.1016/S0167-577X(01)00330-5

[18] G. G. Lee, G. H. Ha and B. K. Kim, "Synthesis of High Density Ultrafine W/Cu Composite Alloy by MethanolThermo Chemical Process," Powder Metal, Vol. 43, No. 1, 2000, pp. 79-82.

[19] S. J. Lim, H. J. Choi and C. H. Lee, "Forming Characteristics of Tubular Product through the Hot-Swaging Process," Journal of Materials Processing Technology, Vol. 209, No. 1, 2009, pp. 283-288.

doi:10.1016/j.jmatprotec.2007.08.086
[20] H. K. Moon, M. C. Lee and M. S. Joun, "An Approximate Efficient Finite Element Approach to Simulating a Rotary Forming Process and Its Application to a WheelBearing Assembly," Finite Elements in Analysis and Design, Vol. 44, No. 1-2, 2007, pp. 17-23. doi:10.1016/i.finel.2007.08.003

[21] J. S. Lee and T. H. Kim, "Densification and Microstructure of the Nanocomposite W-Cu Powders," Nanostructured Materials, Vol. 6, No. 5-8, 1995, pp. 691-694. doi:10.1016/0965-9773(95)00152-2

[22] J. C. Kim and I. H. Moon, "Sintering of Nanostructured W-Cu Alloys Prepared by Mechanical Alloying," Nanostructured Materials, Vol. 10, No. 2, 1998, pp. 283-290. doi:10.1016/S0965-9773(98)00065-8 